REVISTA DE DERECHO UNED, NÚM. 22, 2018

\title{
ANÁLISIS JURÍDICO, ANTECEDENTES Y CONSECUENCIAS DE LA SENTENCIA 177/2016, DEL TRIBUNAL CONSTITUCIONAL, SOBRE PROHIBICIÓN DE LAS CORRIDAS DE TOROS EN CATALUÑA
}

\author{
LEGAL ANALYSIS, BACKGROUND AND CONSEQUENCES \\ OF THE JUDGMENT 177/2016, THE CONSTITUTIONAL COURT'S \\ BAN ON BULLFIGHTING IN CATALONIA
}

\begin{abstract}
ANNA MulÀ
Abogada de la Fundación Franz Weber.

Miembro de la Comisión Promotora y responsable legal de la Iniciativa Legislativa Popular (ILP) de la Plataforma PROU.
\end{abstract}

Resumen: La Ley 28/2010, de 3 de agosto, que prohibió corridas de toros en Catalunya, fue recurrida por el partido popular. Seis años después, el Tribunal Constitucional estimó el recurso mediante la Sentencia 177/2016, del Tribunal Constitucional, analizándolo desde la perspectiva competencial, pero en una clara contradicción e inconsistencia respecto a resoluciones anteriormente dictadas. Se han examinado los elementos de referencia que tomó en consideración el Tribunal para concluir que la previsión autonómica invadía y menoscabía el ejercicio de las competencias estatales en materia de cultura, tomando como foco de atención la tramitación y aprobación de la Ley 18/2013, de 12 de noviembre, para la regulación de la Tauromaquia como patrimonio cultural. La Sentencia sin embargo, reconoce la protección animal como un interés o derecho protegido contrapuesto a la tauromaquia, razón por la cual acaba admitiendo que las Comunidades Autónomas tiene potestades plenas para regular, y no prohibir, las corridas de toros en aras a garantizar la protección y el 
cuidado de los animales. A raíz de esta doctrina instaurada por dicha Sentencia, se ha realizado un análisis jurídico del alcance de la normativa vigente en materia taurina y protección de los animales a nivel estatal y autonómico, que concluye que dentro de los parámetros constitucionales y límites legales, las Comunidades Autónomas están legitimadas para regular dicho espectáculo incorporando aquellos condicionantes que tengan como finalidad la protección de los animales. Tal es el caso de la reciente Ley 9/2017, de 3 de agosto, de regulación de las corridas de toros y de protección de los animales en las Iles Balears.

Text Summary: Act 28/2010, of August 3, which prohibited bullfights in Catalonia, was appealed by the popular party. Six years later, the Constitutional Court (Judgment 177/2016) upheld the appeal analysing it from a competence perspective, but in a clear contradiction and inconsistency with previous rulings. The reference elements that the Court took into consideration to conclude that the autonomic law invaded and impaired the exercise of state powers in the field of culture, are analysed, taking as focus of attention the processing and approval of Law 18/2013, of November 12, for the regulation of Bullfighting as cultural heritage. The judgment recognizes animal welfare as an interest or right protected opposed to bullfighting, admitting that the Autonomous Communities have full powers to regulate bullfights in order to ensure protection and care of the animals. As a result of the doctrine established by the Judgment, a legal analysis of the scope of the current legislation on bullfighting and protection of animals at the State and Autonomic level has been carried out, concluding that the autonomous community are within constitutional parameters and legal limits, entitled to regulate bullfighting incorporating those requirements which are designed to protect the bull. Such is the case of the recent Law 9/2017, of August 3, regulating bullfighting and animal protection in the Balearic Islands.

Palabras clave: Tribunal Constitucional; corridas de toros; protección de los animales.

Keywords: Constitutional Court; bullfights; protection of animals.

Recepción original: 12/12/2017

Aceptación original: 21/02/2018

Sumario: 1. Antecedentes. 2. Recurso del Partido Popular en contra del artículo 1 de la Ley 28/2010. 3. La cuestión competencial como motivadora de la estimación del recurso. 3.1. Conjugación de competencias autonómicas y estatales. 3.2. Medidas de fomento. 4. Regula- 
ción del espectáculo y protección animal. 5. El fallo. 6. El alcance de la normativa taurina de las Comunidades Autónomas después de la Sentencia del Tribunal Constitucional. 7. Conclusión.

\section{ANTECEDENTES}

Fruto de una iniciativa legislativa popular promovida por la Plataforma PROU, con un amplio apoyo nacional e internacional, se aprobó por mayoría absoluta en el Parlamento catalán la Ley 28/2010, de 3 de agosto, de modificación del artículo $6.1 \mathrm{f}$ ) del Decreto legislativo $2 / 2008$, de 15 de abril, por el que se aprueba el texto refundido de la Ley de protección de los animales ${ }^{1}$. El artículo 1 de la Ley 28/2010 prohibió en Cataluña «Las corridas de toros y los espectáculos con toros que incluyan la muerte del animal y la aplicación de las suertes de la pica, las banderillas y el estoque, así como los espectáculos taurinos de cualquier modalidad que tengan lugar dentro o fuera de las plazas de toros»; y el artículo 2 de la Ley 28/2010 suprimió la exclusión de la prohibición de las corridas de toros del artículo 6.2 del Decreto Legislativo 2/2008, de 15 de abril. Esta disposición legal se dictó de acuerdo con la competencia exclusiva sobre espectáculos públicos de la Generalidad de Cataluña contemplada en el artículo 141 del Estatuto de Autonomía de Cataluña (EAC), que habilitó al legislador catalán para ejercer la potestad normativa a fin de establecer un supuesto de prohibición del espectáculo público, y así garantizar la tutela de otro bien jurídico como es la protección de los animales, que prevé el artículo 116 del EAC.

Miles de ciudadanos se dirigieron al Parlament de Catalunya para manifestarse contrarios a los espectáculos taurinos por la existencia de un imperativo ético, moral, social y legal que obliga a evitar sufrimientos, torturas y muerte a los animales. Esta iniciativa siguió un proceso democrático limpio, participativo, argumentado, constructivo y elevó internacionalmente el debate sobre el sufrimiento de los animales en la esfera pública, política y mediática, generando un precedente que ha inspirado a otras instituciones públicas de diversos territorios de todo el mundo con la aprobación de normativas y políticas públicas de protección animal.

La Ley 28/2010 fue dictaminada por el Consejo de Garantías Estatutarias de Catalunya en su dictamen 12/2010, de 5 de julio ${ }^{2}$, que concluyó que se ajustaba a los postulados del Estatuto de Autono-

\footnotetext{
${ }^{1}$ https://www.boe.es/buscar/doc.php?id=BOE-A-2010-13358

${ }^{2}$ https://www.cge.cat/admin/uploads/docs/20130325211542-1.pdf
} 
mía y a la Constitución Española, de acuerdo con la competencia exclusiva de la Generalidad de Cataluña sobre espectáculos públicos y protección de los animales, así como el carácter concurrente en materia de cultura. El dictamen señala que la regulación prevista en la legislación estatal sobre la tauromaquia no puede limitar ni cuestionar el alcance de la competencia de la Generalitat sobre espectáculos y que la prohibición del mismo, adoptada en el ejercicio de una competencia exclusiva en materia de espectáculos, no comporta una lesión a los derechos de los ciudadanos en el ámbito de la cultura. El Parlament de Catalunya ya ejerció la misma competencia sobre espectáculos públicos $-\mathrm{y}$ protección de animales- para adoptar otras medidas prohibitivas de uso de animales en espectáculos públicos, antes y después de la prohibición de corridas de toros, que nunca fueron impugnadas. Así, inicialmente, el apartado 6.1 de la Ley de 3/1988 (actual art. 6.1 del DL 2/2008, de 15 de abril), prohibió las peleas de perros, las peleas de gallos y el tiro al pichón, y fue modificado posteriormente para añadir la prohibición de realizar matanzas públicas de animales (Ley 22/2003, de 4 de julio); la prohibición de las atracciones feriales giratorias con animales vivos atados y otras asimilables (Ley 12/2006, de 27 de julio); y con posterioridad a la Ley impugnada, y haciendo uso de las mismas competencias para prohibir los espectáculos taurinos, el legislador catalán volvió a modificar el art. 6.1 para prohibir el uso de animales en los espectáculos circenses (Ley 22/2015, de 29 de julio).

\section{RECURSO DEL PARTIDO POPULAR EN CONTRA DEL ARTÍCULO 1 DE LA LEY 28/2010}

Cincuenta senadores del grupo parlamentario del Partido Popular (PP) interpusieron un recurso de inconstitucionalidad el 28 de octubre de 2010, contra el art. 1 de la Ley de Cataluña 28/2010, de 3 de agosto. Los senadores recurrentes entendieron que el citado precepto supone, de un lado, la invasión de la competencia estatal para regular el patrimonio cultural español de acuerdo con el art. 149.1.28 de la Constitución Española (CE), en relación con los arts. 149.1.29 y 149.2 $\mathrm{CE}$; de otro lado, la vulneración de las libertades fundamentales reconocidas en los arts. 20.1.a) y c) y $38 \mathrm{CE}$ así como de lo dispuesto en los arts. 44 y $46 \mathrm{CE}$; y, finalmente, la vulneración del principio de unidad de mercado y de libre circulación que se deduce de los arts. 149.1.13 y 139. 2 CE. El Letrado del Parlamento catalán defendió la constitucionalidad de la previsión cuestionada cuya aprobación por el legislador autonómico se fundamenta en la competencia exclusiva 
de la Generalitat en materia de espectáculos públicos (141.3 Estatuto de Autonomía de Catalunya, EAC) y protección y bienestar animal [art. 116.1.d) (EAC], subrayando el carácter concurrente de la competencia en materia de cultura. Seis años después, el Tribunal Constitucional dictó la sentencia 177/2016, de 20 de octubre de $2016^{3}$, estimando el recurso del PP con 8 votos a favor y 3 en contra.

\section{LA CUESTIÓN COMPETENCIAL COMO MOTIVADORA DE LA ESTIMACIÓN DEL RECURSO}

El análisis del recurso por parte del Tribunal Constitucional se hace desde la perspectiva competencial, considerando que el precepto de la Ley catalana invade los artículos 149.1.28 y 149.2 CE, que también responden al mandato del artículo $46 \mathrm{CE}$. Habiendo estimado el recurso por estos motivos, la Sentencia no ha analizado la norma desde la perspectiva de la posible vulneración del art. 149.1.13 en relación con el art. 139.2 CE (principio de unidad de mercado y de libre circulación), ni desde la de la vulneración de los arts. 20.1.d) y $38 \mathrm{CE}$ (libertad artística, libertad de expresión y libertad empresarial). En esta sentencia, el Tribunal Constitucional asegura que el alcance de la competencia exclusiva de la Generalidad sobre espectáculos públicos sólo permite dictar normas reguladoras, pero no prohibitivas, cuando se trata de espectáculos taurinos por ser patrimonio cultural de todos los españoles, y no cuando se trata de otros espectáculos o actividades en donde se utilizan o maltratan animales, que sí podrían ser prohibidos por las Comunidades Autónomas.

\subsection{Conjugación de competencias autonómicas y estatales}

La mayoría del Pleno del Tribunal afirma que el carácter exclusivo de la competencia autonómica en materia de espectáculos públicos junto con la existente en materia de protección animal puede comprender la regulación, desarrollo y organización de tales eventos, lo que podría incluir, desde el punto de vista competencial, la facultad de prohibir determinado tipo de espectáculo por razones vinculadas a la protección animal. Ahora bien, añade, el ejercicio de esa facultad se ve afectada por los títulos competenciales estatales de los artículos 149.2 CE y 149.1.28 CE. Veamos, pues, el contenido y alcance de dichos artículos de la CE. El artículo 149.1.28 atribuye al Estado la competencia

${ }^{3}$ Publicada en el Boletín Oficial del Estado (BOE) n. ${ }^{\circ} 285$, de 25/11/2016 http:// hj.tribunalconstitucional.es/docs/BOE/BOE-A-2016-11124.pdf

(C) UNED. Revista de Derecho UNED, núm. 22, 2018 
en materia de «defensa del patrimonio cultural, artístico y monumental español contra la exportación y la expoliación». Por su parte, el artículo 149.2, otorga al Estado la potestad de «considerar el servicio de la cultura como deber y atribución esencial del Estado y facilitar la comunicación cultural entre las CCAA, de acuerdo con ellas», pero avisando que todo ello se podrá hacer «Sin perjuicio de las competencias que podrán asumir las Comunidades Autónomas» en esta materia de cultura (como de hecho ya lo han hecho en su totalidad).

De esta forma, el Tribunal se ampara en el artículo 149.1.28 para declarar la inconstitucionalidad de la Ley 28/2010, cuando en realidad la finalidad de este artículo es evitar una posible exportación de la tauromaquia en el extranjero o actuar ante el riesgo de apropiación de la tauromaquia de forma violenta o injusta por terceros. En este caso, no hay duda de que la técnica de salvaguarda del patrimonio cultural que tiene el Estado es actuar frente a la exportación o al expolio, lo que indica que está pensado para bienes muebles e inmuebles, y no para algo inmaterial, como es la tauromaquia. Este también es el parecer del voto particular que formulan la Magistrada doña Adela Asua Batarrita y el Magistrado don Fernando Valdés Dal-ré, los cuales detectan una contradicción con resoluciones anteriormente dictadas por el mismo Tribunal en este aspecto en concreto, en el sentido que las medidas estatales de protección de la tauromaquia no parecen encajar en la interpretación estricta que el Tribunal Constitucional ha dado al título estatal del art. 149.1.28, ya que solo puede operar dicha protección ante una eventual «exportación y la expoliación» del patrimonio cultural.

Este voto particular sostiene asimismo que la competencia estatal concurrente de protección de la cultura prevista en el art. 149.2 CE, tampoco es un título suficiente para desplegar un efecto de derogación de una norma autonómica. A la luz de jurisprudencia previa, dicho voto particular denuncia que hasta la fecha, el art. 149.2 CE no había sido interpretado como un título legislativo, y por consiguiente, si el Estado no tiene competencia para legislar con arreglo al art. 149.1 CE, no puede acudir como segunda opción al art. 149.2 CE, con la finalidad de constatar la existencia de una manifestación cultural presente en la sociedad española y, sobre esa base, desplegar una intervención estatal de contenido regulatorio que constriña las competencias autonómicas. Estos magistrados también lamentan que la Sentencia no aclara cuál de los dos citados títulos estatales (149.2 y 149.1.28) es el pertinente para encuadrar el problema, manteniéndose en una calculada ambigüedad. La consecuencia paralela de este enfoque, según este voto particular emitido por ambos magistrados, es la 
restricción de competencias autonómicas, advirtiendo que mediante el planteamiento expuesto, la mayoría del Pleno se acoge a una preocupante línea jurisprudencial en el ámbito de las controversias competenciales, que ya no se limita a expulsar del ordenamiento jurídico aquellas normas autonómicas que incurren en una contradicción normativa frontal e insalvable con el enunciado de una norma perteneciente al bloque de la constitucionalidad, sino que adopta como noción de inconstitucionalidad una difusa idea de menoscabo competencial que aplica a normas autonómicas que cuentan con un amparo competencial inequívoco. Con ello, añade, se redefine la noción de inconstitucionalidad y el juicio de constitucionalidad se desliza por una pendiente peligrosa.

Dicha visión es compartida por la doctrina existente surgida con posterioridad a la sentencia objeto de análisis, a saber:

A juicio del autor ${ }^{4}$, es sorprendente que sean los dos títulos competenciales, el 149.1.28 y el 149.2, ambos relacionados con cierta capacidad estatal de tipo residual y muy concreta en materias culturales, los que permiten al Tribunal Constitucional declarar inconstitucional la norma catalana por violación de las competencias estatales, sin explicar cómo se fusionan los títulos competenciales para provocar este mágico efecto, limitándose a recordar la «dimensión cultural de las corridas de toros». Es decir, que el reparto constitucional de competencias queda alterado en favor del Estado simplemente porque el Estado así lo considera mediante la aprobación de una Ley posterior a la Ley que fue impugnada. Según el autor, «El bajonazo jurídico merece ovación y vuelta al ruedo. Y se culmina, como no puede ser de otra manera, con esta misma unilateralidad y falta de argumentación». A juicio de Andrés Boix, «La decisión es muy criticable jurídicamente, porque altera el reparto constitucional con una argumentación cuestionable (tirando a inexistente), porque modifica toda la jurisprudencia constitucional anterior sin dar cuenta de ello ni explicar el giro habido y, por último, porque se inserta en una línea de recentralización operada desde este órgano que tiene muy magro soporte en la Constitución».

Las críticas también provienen del profesor de Derecho Constitucional $^{5}$, que destaca como novedad relevante de la Sentencia su inconsistencia respecto de la jurisprudencia precedente del mismo Tri-

\footnotetext{
${ }^{4}$ Boix Palop, Andrés. «Ovación y vuelta al ruedo para el Tribunal Constitucional». Blog de la Revista Catalana de Dret Públic [en línia]. [Barcelona: Escola d'Administració Pública de Catalunya], 23 novembre 2016

${ }^{5}$ Ridao Martín, Joan. «Toros: entre l'espectacle públic, el patrimoni cultural i la protecció animal». Revista Catalana de Dret Públic, núm. 54 (juny 2017), p. 171-184, DOI.
}

(C) UNED. Revista de Derecho UNED, núm. 22, 2018 
bunal, en relación al alcance y a la forma de articulación de las específicas competencias concurrentes del Estado. A tal efecto, sólo hay que ver que la exhortación contenida en el artículo 149.2 CE no era considerada una habilitación estatal específica sino un mandato dirigido al conjunto de los poderes públicos (STC 49/1984, FJ 6).

Siguiendo con este razonamiento, el voto particular del magistrado don Juan Antonio Xiol Ríos delata la falta de motivación y concreción en la decisión tomada para estimar el recurso del Partido Popular. Así, según este magistrado, si bien la opinión de la mayoría reconoce que la norma catalana impugnada tiene una conexión con los títulos competenciales exclusivos de la Generalitat relativos a la materia de protección de los animales y juego y espectáculos, ninguna consecuencia se extrae de ello y simplemente se admite que estas competencias autonómicas exclusivas pueden ser desplazadas por la competencia estatal de protección de la cultura (y ello, a pesar de que el Estado no tiene una competencia básica, sino concurrente con las CCAA en esta materia). Para este magistrado, no se puede obviar que la asunción de competencias autonómicas exclusivas en materia de espectáculos públicos arrastra indefectiblemente de manera completa los ámbitos legislativo y de ejecución. Y ello es así porque, por una parte, la Constitución no menciona entre los títulos competenciales los espectáculos taurinos o los espectáculos públicos y por otra parte, la Ley y el Reglamento taurino estatales tienen carácter supletorio. En esta línea, se recuerda que la disposición adicional de la Ley 10/1991, de 4 de abril, de potestades administrativas de espectáculos taurinos declara que «lo establecido en la presente Ley será de aplicación general en defecto de las disposiciones específicas que puedan dictar las Comunidades Autónomas con competencia normativa en la materia», lo que se reiteró en el Real Decreto 145/1996, de 2 de febrero, por el que se aprueba el vigente Reglamento de Espectáculos taurinos.

Por lo expuesto, en el escenario constitucional, la tauromaquia no tendría cabida en ninguno de los artículos mencionados de la CE.

Para delimitar la competencia estatal en materia de cultura y concluir que la previsión autonómica invade y menoscaba el ejercicio de las competencias estatales en materia de cultura, el Tribunal también se ha valido de los siguientes elementos de análisis:

1) En primera lugar, la aserción de que «la tauromaquia tiene una indudable presencia en la realidad social de nuestro país», totalmente infundada y con un alto nivel de subjetividad en su cometido, contradiciéndose además cuando más adelante se confirma en la Sentencia «la existencia de rechazo, desafección 
o desinterés de parte de la población respecto a este espectáculo». Así es, en España, se ha asistido a un aumento de la conciencia ciudadana para la protección íntegra de los animales, siendo testigo de forma paralela de una creciente declaración de ciudades antitaurinas, de prohibiciones de festejos taurinos, de la falta de renovación generacional de los espectadores y de la ausencia generalizada de apoyo social. Todo ello ha supuesto un daño a la imagen de España en el extranjero, que se identifica por ser un país que mantiene una actividad extremadamente cruel con los animales. El arraigo de las corridas de toros en estos años también ha disminuido en los otros países donde la tauromaquia todavía es legal. Estas circunstancias han dado lugar a una marcada y progresiva decadencia de los espectáculos taurinos en todo el mundo, con altas pérdidas en el sector, provocada por la falta de legitimación legal y social de esta actividad impropia con valores de la actual sociedad.

2) También encuentra justificación para derogar la Ley catalana la mayoría del Tribunal en la exposición de motivos de la Ley 10/1991, de 4 de abril, de potestades administrativas de espectáculos taurinos, que aludía a la conexión de tales espectáculos con el fomento de la cultura que corresponde al Estado en atención a la tradición y vigencia cultural de la fiesta de los toros. Al respecto, el Tribunal Constitucional Español resolvió en un fallo anterior, concretamente, en la Sentencia de 4/10/1990, que «los preámbulos o exposiciones de motivos carecen de valor normativo», por lo que nuevamente en esta ocasión se estaría contradiciendo precedentes constitucionales tomadas por el mismo Tribunal en otros casos con distinta temática.

3) Asimismo, la Sentencia también hace una remisión explícita al deber que a los poderes públicos incumbe de garantizar la conservación y la promoción del enriquecimiento del patrimonio histórico y cultural. Todo ello en virtud del artículo $46 \mathrm{CE}$, que reza: «Los poderes públicos garantizarán la conservación y promoverán el enriquecimiento del patrimonio histórico, cultural y artístico de los pueblos de España y de los bienes que lo integran, cualquiera que sea el régimen jurídico y su titularidad. La ley penal sancionará los atentados contra este patrimonio». Sin embargo, si acudimos al vigente Código Penal, estos presuntos atentados se refieren únicamente a 3 conductas punibles: 1) Los que derriben o alteren gravemente edificios singularmente protegidos. 2) Los que produzcan daños en un archivo, registro, museo, biblioteca, centro docente, gabinete 
científico, institución análoga o en bienes de valor histórico, artístico, científico, cultural o monumental. 3) Los que causen daños en yacimientos arqueológicos. Nada que ver con las corridas de toros o la tauromaquia.

4) Finalmente, la mayoría del los miembros del Tribunal Constitucional valoran la existencia de instrumentos normativos aprobados con posterioridad a la Ley impugnada «como elementos de referencia que deben tomarse en consideración en este proceso, en línea de semejanza con la doctrina que este Tribunal ha establecido en relación con el denominado ius superveniens». Dicha doctrina postula que la norma catalana controvertida ha de enjuiciarse teniendo en cuenta las normas en vigor en el momento en que se dicta la sentencia, aunque no estuvieran en vigor en el momento en que se aprobó la Ley impugnada, es decir, la Ley 18/2013, de 12 de noviembre, para la regulación de la Tauromaquia como patrimonio cultural y en menor medida, la Ley 10/2015, de 26 de mayo, para la salvaguardia del Patrimonio Cultural Inmaterial.

Los votos particulares emitidos por los tres magistrados mencionados también realizan observaciones dirigidas a la utilización de la aprobación de la Ley 18/2013, de 12 de noviembre, para la regulación de la tauromaquia como patrimonio cultural. Para el voto particular de don Juan Antonio Xiol Ríos, la insuficiencia de la 10/1991, de 4 de abril, para justificar cualquier tipo de competencia estatal apta para impedir una decisión autonómica de prohibición de los espectáculos taurinos, propició la aprobación de la Ley 18/2013, de 12 de noviembre. Evoca dicho magistrado que en el momento de aprobación de la Ley catalana, ninguna competencia estatal exclusiva o básica se había desarrollado o alegado en confrontación con esas capacidades competenciales autonómicas ni tampoco la competencia estatal concurrente de fomento de la cultura del art. 149.2 CE había sido ejercida de ninguna manera que impidiera la libre decisión legislativa de las comunidades autónomas en la materia. De tal manera que si el recurso del PP se hubiera resuelto previamente a la aprobación de la Ley 18/2013, de 12 de noviembre, las posibilidades de su estimación hubieran sido nulas. Esa es sin duda la razón, esgrime este magistrado, por la que de una manera inequívoca se ha puesto toda la fuerza argumental de la Sentencia en una norma sobrevenida como es la Ley 18/2013, con el agravante de que se hace uso de la doctrina del ius superveniens o derecho sobrevenido de manera improcedente en un conflicto competencial como el planteado: improcedente porque el supuesto en el que se sustenta la senten- 
cia es propio de los conflictos competenciales que se plantean cuando el ejercicio de las competencias de desarrollo de las comunidades autónomas se confronta con el ejercicio de competencias básicas por parte del Estado, y éste no es el tipo de conflicto competencial que se plantea en este recurso, en que no cabe apreciar que el Estado disponga de competencia básica alguna para que su decisión de protección de la tauromaquia pueda resultar prevalente con efecto de desplazamiento sobre las competencias autonómicas de protección animal y de espectáculos públicos. Por su parte, los magistrados doña Adela Asua Batarrita y don Fernando Valdés Dal-ré añaden que la definición legal de tauromaquia en la Ley 18/2013, como objeto de protección, es amplísima («conjunto de conocimientos y actividades artísticas, creativas y productivas, incluyendo la crianza y selección del toro de lidia») y por ello la norma estatal que protege la tauromaquia se puede cumplir de muchas formas y en ningún momento impone que se deban celebrar corridas de toros.

Por consiguiente, concluyen, que la conservación de la tauromaquia como mandato normativo no resulta idónea para declarar inconstitucional una norma autonómica que establece una prohibición precisa y que cuenta con un amparo inequívoco en las competencias de la Comunidad Autónoma. De este modo, la Sentencia del Tribunal Constitucional trata las corridas de toros como patrimonio cultural digno de protección en todo el territorio nacional amparándose mayormente en la Ley 18/2013, de 12 de noviembre, dictada también como consecuencia de una Iniciativa Legislativa Popular (ILP) mediante la cual los firmantes pidieron al Congreso de los Diputados que se declararan las corridas de toros «Bien de Interés Cultural» (BIC), amparándose en la normativa que regula la tramitación y/o declaración de un bien de interés cultural, la Ley 16/1985, de 25 de junio, del Patrimonio Histórico Español. A pesar de que en el Pleno celebrado en el Congreso de los diputados el 22 de febrero de 2012 donde se debatió la admisión a trámite de la ILP, el PP votó en bloque a favor del texto inicial, luego tuvo que modificar el texto completamente al admitir que provocaría una cascada de recursos ante el Tribunal Constitucional. Durante esta primer fase del debate parlamentario, ya se puso de manifiesto que el Estado carecía de competencias para tramitar y aprobar la ILP ya que la declaración de Bien de Interés Cultural corresponde a las CCAA, por lo que en caso contrario, el Congreso de los Diputados estaría excediéndose en sus competencias. Como antecedente fundamental en dicho discurso, se recuperó el rechazo previo de una moción planteada por el PP en el Senado en el año 2010 para instar al Gobierno a declarar las corridas de toros Bien de Interés Cultural, por tratarse 
de una competencia transferida a las $\mathrm{CCAA}^{6} \cdot{ }^{7}$ Por este motivo, se descartó utilizar el vocablo Bien de Interés Cultural en el texto y empezó a hablarse de "patrimonio cultural». No obstante, durante el trámite de las comparecencias parlamentarias de expertos celebradas en la Comisión de Cultura del Congreso de los Diputados los días 10 y 11 de julio de 2013, acerca de esta proposición de ley ${ }^{8}$, quedó patente asimismo que el Estado central carecía de competencias en materia taurina, en materia de espectáculos públicos y concurría con las CCAA en materia de cultura, así que cualquier decisión sobre cultura la había de tomar en connivencia con las CCAA. En esta dirección, la Constitución española no podía motivar la declaración unilateral de tauromaquia como patrimonio cultural para imponer una unidad cultural por parte del Estado en todo el territorio español, ya que la Constitución alude a otras Administraciones, por la misma naturaleza del carácter concurrente que tiene la competencia de cultura, propio de un Estado descentralizado, a través de la competencia de las CCAA en materia de cultura por parte de la CE que reconoce el art. 149.2.

De lo anterior se desprende que ningún precepto constitucional habilitó en España a declarar la tauromaquia como patrimonio cultural de todos los españoles digno de protección, una actividad que en lugar de generar consensos, divide a la sociedad española en un contexto constitucional que ha optado por una España plural, territorial, jurídica y cultural y donde se han asumido por la totalidad de las comunidades autónomas en sus estatutos de autonomía con carácter de exclusivas las competencias en materia de espectáculos públicos. Además, los espectáculos taurinos siguen siendo una excepción en el marco de la legislación de protección de los animales, por lo que no es pertinente extender esta excepcionalidad a la generalidad a través de la declaración legal de los espectáculos taurinos como patrimonio cultural.

${ }^{6}$ El Senado rechaza proteger los toros como Bien de Interés Cultural http://www. rtve.es/noticias/20101006/senado-rechaza-gobierno-declare-toros-bien-interes-cultu$\mathrm{ral} / 359502 . \mathrm{shtml}$

${ }^{7}$ A sensu contrario, ante la declaración BIC por parte de las CCAA de Murcia, Madrid, Castilla la Mancha, Castilla y León, en virtud de su propia legislación autonómica, no se conoce reacción alguna por parte del Estado en contra de dichas medidas adoptadas, ni mucho menos que hayan sido objeto de impugnación por dicha Administración estatal aduciendo invasión de competencias.

${ }^{8}$ Acceso a las comparecencias íntegras:

10/7/2013: http://www.congreso.es/public_oficiales/L10/CONG/DS/CO/DSCD-10CO-374.PDF

11/7/2013: http://www.congreso.es/public_oficiales/L10/CONG/DS/CO/DSCD-10CO-376.PDF 
A pesar de ello, no deja de sorprender que la Ley se aprobó, en la Comisión de Cultura con competencia legislativa plena el 2 de octubre de 2013, siendo el resultado de la votación de 24 votos a favor (PP y UPN), 6 en contra (U-ICV-CHA, ERC, CiU y PNV) y 14 abstenciones (PSOE y UPyD). ${ }^{9}$

A todo ello, hay que añadir que el concepto de patrimonio cultural, como un conjunto de los bienes que forman parte de prácticas sociales que se han de transmitir a la siguiente generación para asegurar su permanencia indefinida en el tiempo, es subjetivo y dinámico y no depende de los bienes o entidades materiales o inmateriales, sino de los valores que la sociedad les atribuyen en cada momento de la historia y que determinan qué hay que proteger y conservar para la posteridad. Hoy en día, la protección de los animales es un valor para la sociedad, además de un deber legal que se extiende a todos los poderes públicos. En este contexto, el Informe Mundial de la Organización de las Naciones Unidas para la Educación, la Ciencia y la Cultura (UNESCO) sobre la diversidad cultural (2010), máxima autoridad mundial en el ámbito de la cultura, ha declarado lo siguiente:

«Transcurrieron prácticamente siete décadas del siglo XX antes de que se llegara a comprender que las culturas son entidades que se transforman. Anteriormente, había una tendencia a considerar que permanecían esencialmente inmutables y que su contenido se «transmitía» por varios canales, como la educación o las prácticas incoativas de diversos tipos. En la actualidad hay una comprensión más cabal de la cultura en cuanto proceso: las sociedades cambian según pautas que les son peculiares. Estas consideraciones abundan en pro de un nuevo enfoque de la diversidad cultural, un enfoque que tenga en cuenta su índole dinámica y los desafíos a la identidad relacionados con el carácter permanente del cambio cultural. Las culturas no son entidades estáticas o cerradas en sí mismas. Una de las principales barreras que obstaculizan el diálogo intercultural es nuestro hábito de concebirlas como algo fijo, como si hubiera líneas de fractura que las separaran.»

Efectivamente, la cultura se transforma y la evolución cultural genera progreso. No se trata de negar la existencia de una tradición cultural que consiste en prácticas de maltrato animal, pero el argumento de mayor peso no es el de la existencia de una tradición, de una continuidad cultural sin revisión de los valores éticos que dan lugar al reconocimiento de bienes que son dignos de protección jurídica y, correlativamente, de conductas que no deben ser permitidas porque suponen un daño inadmisible, lo que postula su prohibición.

${ }^{9} \mathrm{El}$ debate definitivo se puede leer en el siguiente enlace http://www.congreso.es/ public_oficiales/L10/CONG/DS/CO/DSCD-10-CO-417.PDF\#page=2

(C) UNED. Revista de Derecho UNED, núm. 22, 2018 
Hoy en día, ha cambiado la percepción acerca de esas prácticas al advertir que suponen la existencia de un mal: la crueldad, ante el que el Derecho no puede ser indiferente. Por eso, aun reconociendo la existencia de prácticas que implican sufrimiento y maltrato animal y que forman parte de la cultura de muchos países y otras que son consideradas una de las expresiones de la cultura hispánica en todo el mundo, como los espectáculos taurinos, es indudable que su mantenimiento contribuye a fomentar una educación y una cultura contraria al respeto a la vida en todas sus formas y expresiones. En nombre de la cultura, es legítimo maltratar a un animal en España y en otros lugares donde el estado español ha exportado las corridas de toros, mientras que esa conducta es considerada delito en el resto de naciones del mundo.

El preámbulo de dicho cuerpo legal reconoce que la tauromaquia está supeditada a los cambios sociales que ya se vienen experimentando en este ámbito: "La fiesta de los toros y los espectáculos taurinos populares son algo vivo y dinámico, sujetos a constante evolución, sin que se puedan hacer conjeturas sobre de qué manera se adaptarán a las sensibilidades cambiantes de nuestros tiempos $\mathrm{u}$ otros venideros».

Este carácter cambiante y activo de todos los bienes que integran el patrimonio cultural se reitera en la Ley 10/2015, de 26 de mayo, para la salvaguardia del Patrimonio Cultural Inmaterial, cuyo art. 3 enumera los principios generales que han de regir las actuaciones de salvaguardia de los poderes públicos sobre los bienes del patrimonio cultural, subrayando «El dinamismo inherente al patrimonio cultural inmaterial, que por naturaleza es un patrimonio vivo, recreado y experimentado en tiempo presente y responde a prácticas en continuo cambio, protagonizadas por los individuos y los grupos y comunidades».

Queremos concluir este apartado abordando la idea de que con toda claridad, otra de las finalidades de la introducción del concepto de «patrimonio cultural» en la Ley 18/2013, de 12 de noviembre, fue impulsar los trámites para incluir los espectáculos taurinos en la lista del Patrimonio Cultural de la UNESCO, un organismo especializado y dependiente de la Organización de Naciones Unidas (ONU), cuyas actividades culturales buscan la salvaguarda del Patrimonio Cultural Inmaterial de la Humanidad con la finalidad de preservarlo para las generaciones futuras. Este fue el mandato que el poder legislativo le dio al Gobierno español en la Disposición Final Primera de la Ley 18/2013, a través de las «reformas normativas necesarias para recoger, dentro de la legislación española, el mandato y objeti- 
vos de la Convención para la Salvaguardia del Patrimonio Cultural Inmaterial de la UNESCO». No obstante, las corridas de toros y espectáculos anexos no encajan ni en el espíritu ni en la letra de los requisitos que han de cumplir las distintas formas de expresión cultural que aspiran a ser distinguidas como Patrimonio cultural por parte de este organismo internacional. Esta protección se hace a través de la Convención para la salvaguarda del patrimonio cultural inmaterial, hecha en París, el 17/10/2003 ${ }^{10}$, pero requiere de ciertos requisitos, como el que exige que el patrimonio cultural que se pretenda salvaguardar cumpla con el artículo 2 de dicha Convención, es decir que "sea compatible con los instrumentos internacionales de derechos humanos existentes y con los imperativos de respeto mutuo comunidades, grupos e individuos», cuestión que no se cumple desde que la ONU ha considerado la tauromaquia una actividad violenta a la que se expone al niño desde pequeño vulnerando sus derechos a la integridad física, mental y emocional, tomando como sustento legal la Convención sobre los Derechos del Niño, adoptada por la Asamblea General de Naciones Unidas en su resolución 44/25, de 20 de noviembre de 1989.

Enlazando con lo anterior, una de las justificaciones normativas de la aprobación de la Ley 18/2013, reside, según su preámbulo, en «los tratados internacionales en la materia» (además de los artículos ya analizados de la $\mathrm{CE}$ ). ¿Qué convenciones internacionales tratan las corridas de toros/tauromaquia? Ninguno, aunque hay una afección directa, como se ha anunciado, a sensu contrario, en la Convención sobre los Derechos del Niño, cuyo objeto es proteger los derechos humanos de las personas menores de edad. Dicha Convención ha sido la base para que Naciones Unidas, a través del Comité de los Derechos del Niño, inste a la comunidad internacional a proteger a las personas menores de 18 años de la violencia de la tauromaquia. Así se ha pronunciado dicho Comité en la formulación de las Observaciones Finales sobre el nivel de cumplimiento y aplicación de la Convención sobre los derechos del niño de 6 países taurinos - examinados hasta la fecha- $\left(\right.$ Portugal $^{11}$, Colombia $^{12}$, México $^{13}$, Perú $^{14}$ y

\footnotetext{
${ }^{10} \mathrm{http}: / /$ unesdoc.unesco.org/images/0013/001325/132540s.pdf

${ }^{11} \mathrm{http} / / /$ tbinternet.ohchr.org/_layouts/treatybodyexternal/Download. aspx?symbolno=CRC/C/PRT/CO/3-4\&Lang=En

$12 \mathrm{http}: / /$ tbinternet.ohchr.org/_layouts/treatybodyexternal/Download. aspx?symbolno=CRC/C/COL/CO/4-5\&Lang=Sp

${ }^{13} \mathrm{http}$ ://tbinternet.ohchr.org/_layouts/treatybodyexternal/Download.aspx?symbol $\mathrm{no}=\mathrm{CRC} \% 2 \mathrm{FC} \% 2 \mathrm{FMEX} \% 2 \mathrm{FCO} \% 2 \mathrm{~F} 4-5$

$14 \mathrm{http}$ ://tbinternet.ohchr.org/_layouts/treatybodyexternal/Download. aspx?symbolno=CRC/C/PER/CO/4-5\&Lang=En
} 
Francia ${ }^{15}$, Ecuador ${ }^{16}$ y España ${ }^{17}$ ), en las que se ha incorporado un pronunciamiento, en el apartado relativo a la «Violencia en contra de los niños», relativo a la vulneración de los derechos del niño cuando participa y asiste a espectáculos taurinos, instando a adoptar las medidas legislativas, administrativas y educativas pertinentes para hacer efectivo dicho pronunciamiento. Este hecho refuerza la convicción de que la tauromaquia es una actividad violenta y perjudicial para la sociedad y una fuente de educación en la violencia e imposibilita que dicha actividad pueda formar parte del patrimonio cultural de las naciones que han ratificado la Convención sobre los Derechos del niño.

\subsection{Medidas de fomento}

La actividad de la tauromaquia está fuertemente subvencionada. Por ello, no resulta desechable otra de las conclusiones a las que llega la Sentencia, consistente en que las Comunidades Autónomas no están obligadas a «adoptar medidas concretas de fomento en relación a las corridas de toros y otros espectáculos similares». Es decir que en el ámbito territorial pertinente, se desprende que podrían frenarse las medidas de financiamiento público dirigidas a la tauromaquia, como pueden ser subvenciones, inversiones, beneficios fiscales o cualquier otra medida de fomento público relacionadas directa o indirectamente con la cría y selección de los toros utilizados, organización y divulgación de las actividades o rehabilitación o mantenimiento de plazas de toros, entre otras. Al respecto, el Parlamento Europeo ha aprobado por mayoría absoluta poner fin a las cuantiosas subvenciones provenientes de la UE destinadas a las actividades relacionadas con la tauromaquia por considerarla una actividad cruel que hay que desarraigar de las costumbres de los países de la Unión Europea (lamentablemente, la Comisión Europea todavía no ha materializado dicha petición del Parlamento en ninguna medida concreta, esgrimiendo argumentos técnicos difíciles de solventar a corto plazo que podrían comportar la reforma de la Política Agraria Común -PAC_-). De lo que no cabe duda es que en los últimos años se han ido eliminando en algunos territorios las ayudas destinadas a espectáculos taurinos, lo que ha comportado la desaparición de estos espectáculos a nivel local.

${ }^{15} \mathrm{http} / / /$ tbinternet.ohchr.org/_layouts/treatybodyexternal/Download.aspx?symbol no $=\mathrm{CRC} \% 2 \mathrm{FC} \% 2 \mathrm{FFRA} \% 2 \mathrm{FCO} \% 2 \mathrm{~F} 5 \& \mathrm{Lang}=\mathrm{en}$

${ }^{16} \mathrm{http}$ //tbinternet.ohchr.org/Treaties/CRC/Shared\%20Documents/ECU/INT_

CRC_COC_ECU_29108_E.pdf

${ }^{17} \mathrm{http}: / /$ tbinternet.ohchr.org/Treaties/CRC/Shared\%20Documents/ESP/CRC_ CO_5-6_30177_E.pdf 


\section{REGULACIÓN DEL ESPECTÁCULO Y PROTECCIÓN ANIMAL}

Respecto a la protección de los animales, el magistrado don Juan Antonio Xiol Ríos en su voto particular afirma que la cuestión de fondo que ha emergido como un tema competencial es el conflicto entre una cultura emergente ambientalista y de protección de los animales, en clara contradicción con una cultura defensora de la tauromaquia. La tauromaquia no es una manifestación cultural neutral desde el punto de vista del sistema de valores que representa, asevera, ya que está enfrentada con la protección de los animales alineada con la demanda de una sociedad avanzada también en el contexto internacional.

Es remarcable que al final de la Sentencia, la decisión adoptada por la mayoría en la que se sustenta la misma, reconoce que el mantenimiento de esta manifestación cultural puede tener en cuenta otros intereses y derechos protegidos a veces contrapuestos, que han de ser también adecuadamente ponderados. Se refiere, como no podía ser de otra manera, a la protección de los animales, y por ende, el Tribunal aclara que la competencia sobre espectáculos públicos y protección de los animales permite a las Comunidades Autónomas las siguientes potestades plenas:

\section{1) «Regular el desarrollo de las representaciones taurinas».}

\section{2) «Establecer requisitos para el especial cuidado y atención} del toro bravo".

Así se manifiesta taxativamente el Tribunal Constitucional en su FJ 7:

«Ello no significa que la Comunidad Autónoma, no pueda, en ejercicio de sus competencias sobre ordenación de espectáculos públicos, regular el desarrollo de las representaciones taurinas, como, de hecho, ya ha realizó la Comunidad Autónoma en una Ley previa que limitaba el acceso a las corridas a los mayores de 14 años y restringía sus celebraciones a las plazas ya construidas; ni tampoco que, en ejercicio de su competencia en materia de protección de animales, pueda establecer requisitos para el especial cuidado y atención del toro bravo».

De este modo, la cuestión competencial sobre las atribuciones competenciales del binomio Estado-CCAA, queda zanjada en esta sentencia que ha delimitado la capacidad legislativa y reglamentaria de las Comunidades Autónomas en materia taurina, sin más límite que el de impedir que dichas administraciones prohíban de plano el espectáculo. ${ }^{18}$

${ }^{18}$ Por esta razón, esta Sentencia ha sido calificada por los sectores taurinos y los abogados especializados en materia taurina, como la «Sentencia de Muerte de la

(C) UNED. Revista de Derecho UNED, núm. 22, 2018 
Ello supone que en estos territorios se dispone de plena autonomía y libertad para regular el desarrollo de los festejos taurinos y para determinar los aspectos a los que deban sujetarse dichas representaciones taurinas y las condiciones de protección de los animales para eliminar/minimizar el sufrimiento del toro (por ejemplo, suprimiendo el tratamiento del tercio de varas o banderillas y/o la muerte de la res).

Ante la indefinición del alcance de la competencia estatal para obligar a las Comunidades autónomas a celebrar espectáculos taurinos, y ante la no concreción de la magnitud y significación para regular las condiciones de dichas representaciones taurinas por parte de las Comunidades Autónomas, estos requisitos, podrían comprender aspectos que se extienden al embarque, transporte y desembarque para evitar lesiones y sufrimientos a las reses; edad de los toros que participan en el espectáculo; reconocimientos previos al espectáculo sobre las condiciones de bienestar físico y psíquico del animal, edad, peso y estado íntegro de las astas; condiciones de los corrales y chi-

tauromaquia» «Toros en Cataluña: sentencia de muerte». Luis Hurtado, Profesor de Derecho del Trabajo, Universidad de Sevilla. http://www.taurologia.com/toros-cataluna-sentencia-muerte-4366.htm

¿Cuál es, entonces, el motivo de mi preocupación? Pues que este razonamiento se acompaña de un par de afirmaciones extensivas de las competencias autonómicas y, sobre todo, de un completo silencio, en cambio, sobre cuál sea el contenido mínimo de la competencia estatal para la conservación de dicho patrimonio común. Las afirmaciones a que me refiero, si no quedan desvirtuadas en el texto íntegro de la sentencia, serán más peligrosas para las corridas que si la prohibición no hubiese sido recurrida. Porque enseñarían el camino «bueno» a seguir para una futura supresión indirecta de aquéllas: a) que la competencia sobre espectáculos públicos permite a las comunidades autónomas «regular el desarrollo de las representaciones taurinas»; b) que su competencia sobre protección de los animales les permite, además «establecer requisitos para el especial cuidado y atención del toro bravo». No dice el TC, en cambio, que esas competencias autonómicas tengan algún límite. ¿Qué les impide regular el desarrollo de la corrida sin que ésta incluya la suerte suprema? ¿Qué les impide modificar después esa regulación y suprimir también la suerte de la pica? ¿Qué les impide implantar en el tercio de banderillas unas con ventosas en lugar de arpón? ¿Acaso una regulación autonómica semejante no acabaría con los toros, sin necesidad prohibirlos?

«De cómo el Constitucional condena a muerte la tauromaquia en Cataluña». Antonio Lorca http://cultura.elpais.com/cultura/2016/11/22/el_toro_por_los_cuernos/1479794554_227066.html «Si las Comunidades Autónomas, como dice el TC sin necesidad, pueden regular el desarrollo de los festejos taurinos», prosigue, «nada impide a Cataluña suprimir la suerte suprema o el tercio de varas o banderillas, que son elementos fundamentales de la corrida». «Determina la nulidad de la prohibición, pero reconoce la competencia ilimitada para que Cataluña pueda hacer otra cosa». "La sentencia del TC», añade, "consolida la posibilidad de que en ciertos territorios se prohíba de facto la fiesta; de hecho, si se regula será para desnaturalizarla o no autorizarla, y cada vez estará más cuestionada porque es una fiesta difícil de comprender». 
queros para asegurar el bienestar de los animales durante su estancia; reducción del número de los animales por espectáculo; la celebración del espectáculo por profesionales taurinos que no implique sufrimiento y muerte del animal en público ni su matanza posterior; medidas de sensibilización y restricción del acceso a los menores de edad y elementos para garantizar la salud y la seguridad de las persones y los animales, entre otras muchas.

Ya en el debate de la Comisión del Parlament de Catalunya acerca de la ILP que desembocó en la Ley cuya anulación ha sido declarada en parte por el Tribunal Constitucional, el profesor Dr. Javier de Lucas en su comparecencia celebrada el 4 de marzo de 2010 señaló $^{19}$ : «...El debate más abierto tiene que ver con las dos últimas formas de racionalidad, pues lo que más nos importa es si se puede (y debe) alcanzar los fines sociales perseguidos y si las conductas que se prescriben y la propia finalidad de la ley presuponen valores susceptibles de justificación ética. No de cualquier ética: de la ética pública, de la que es relevante en términos jurídicos. Sobre una y otra cuestión, la duda más relevante se refiere quizá a la limitación de la libertad. Porque el Derecho - como nos recuerda una concepción que arranca de Cicerón (legum servi sumus ut liberi esse possumus) y alcanza su mejor expresión en Kant y en JS Mill, el padre del mejor liberalismo- no es otra cosa que un artefacto para hacer posible la conjugación de la libertad de cada uno con la de los demás. Y eso no es posible sin regular el ejercicio de esas libertades, sin establecer controles y ponderación entre los intereses $y$ bienes en conflicto y, por ende, en algunos casos, prohibiciones. El Código penal -la "Constitución negativa", como se lo ha denominado- es eso. Lo importante es que se garantice el principio básico de favor libertatis. Pero eso no excluye el carácter justificado de limitaciones de la libertad, aunque obliga a la carga de la prueba a quien quiere limitar la libertad porque considera necesaria y adecuada esa limitación. La justificación básica de la limitación es la enunciada por Mill, que es la misma que inspiró un celebre texto de Jeremias Bentham el padre de la moderna teoría y técnica de la legislación ya en 1789 (Introduction to the Principles of Moral and Legislation): evitar causar daño a intereses, necesidades o, digámoslo así, bienes, jurídicamente relevantes. Las aportaciones de la biología, la etología o la neurociencia, han demostrado más que contundentemente que esta tradición causa daños no justificables, pues los argumentos y pruebas científicas son difícilmente ob-

${ }^{19}$ Diari de Sessions del Parlament de Catalunya Sèrie C - Número 757, de 4 de març de 2010. https://www.parlament.cat/document/nom/08c757.pdf Extracto de la comparecencia en el Parlament de Catalunya del Prof. Dr. Javier de Lucas. Catedrático de Filosofía del Derecho y Filosofía Política. Director del Instituto de Derechos Humanos (IDH) Universidad de Valencia.

(C) UNED. Revista de Derecho UNED, núm. 22, 2018 
jetables. El daño causado a los toros en la fiesta, en el espectáculo de las corridas de toros, es irrebatible. Y por ello es un daño jurídica (no sólo éticamente) inadmisible: es maltrato y tortura, aunque también sea arte y tradición. La violencia y la guerra llenan la inspiración del arte, la fiesta, de la filosofía, del pensamiento. No por ello defendemos la violencia ni la guerra. Y su única justificación (la que permite hablar de violencia justa, guerra justa, expresiones que, a juicio de muchos de nosotros serían un auténtico oximoron) se encontraría en el carácter de medio necesario para evitar un daño peor. Pero eso no es el caso en las corridas de toros. Precisamente es ese el sentido de la afirmación de Bentham cuando se pregunta por la existencia de deberes y aun de derechos para con los animales, basándose en el mandato básico de no infligir sufrimiento gratuito (...). No se discute que según lo demuestra cierta tradición arraigada, a no pocos puede parecerle bello ese espectáculo. En ese caso, se trata de una belleza cuyo coste no es, no debe ser asumible si pretendemos una sociedad mejor. No hay racionalidad juridica que pueda apoyarse sólo en la existencia de un hábito (por arraigado que fuera, por ampliamente compartido) si ese hábito causa un daño relevante a un bien a su vez relevante. $Y$ además, junto al daño físico y psíquico infligido a los toros, cabe añadir el daño desde el punto de vista de la educación de la ciudadanía. Porque un espectáculo público que extrae su belleza de una muestra tal de violencia y aún de crueldad (y no de una mera representación), no contribuye a construir una sociedad más respetuosa con el sufrimiento, menos violenta, menos cruel. Una sociedad como la que necesitamos, por nuestro propio bien». "La cuestión, a mi juicio, no es si debemos prohibir o no las corridas de toros, los espectáculos que implican malos tratos, tortura y muerte de los toros; la cuestión es cuánto tiempo podemos seguir sin hacerlo, sin adoptar esta prohibición, asumiendo de esa manera un mal que se infringe, como he tratado de argumentar brevisimamente, a los toros y a la sociedad. ¿Cuánto retrasaremos una decisión que me parece la única razonable para situarnos en la dirección del progreso social y moral a la que el derecho debe servir?».

La comparecencia del Prof. Pablo de Lora, celebrada en la Comisión del Parlament de Catalunya el día 4 de marzo de $2010^{20}$, abundó en la crueldad del espectáculo para apoyar su prohibición: «Piensen por un momento lo que se dirá dentro de algunos años, no muchos, sobre la actual pervivencia de las corridas de toros, sobre la crueldad

${ }^{20}$ Diari de Sessions del Parlament de Catalunya Sèrie C - Número 757, de 4 de març de 2010. https://www.parlament.cat/document/nom/08c757.pdf Extracto de la comparecencia en el Parlament de Catalunya del Prof. Pablo de Lora. Profesor Titular de Filosofía del Derecho de la Universidad Autónoma de Madrid. Autor del libro «Justicia para los animales» (2003). 
institucionalizada que supone que el ordenamiento jurídico no solo siga permitiendo la inflicción de sufrimiento gratuito a mamíferos superiores, sino que se regule con precisión reglamentaria cuánto han de medir y qué horma han de tener los instrumentos de la tortura hodierna...». Y acentuó su discurso en la no justificación de la coexistencia de otras formas crueles con las corridas de toros para mantenerlos impasibles: "Decir, sin embargo, que las corridas de toros deben mantenerse porque existen otras maneras más crueles de tratar a los animales es tanto como señalar que quien ha cometido un robo no debe ser castigado porque todavía campan por sus respetos asesinos y violadores varios». No parece que pueda ser una razón para oponerse a la abolición el hecho de que otras formas de maltrato sean más graves. Con semejante criterio, que tienen el efecto de impedir que nos ocupemos de lo siguiente en la lista de nuestras prioridades éticas hasta tanto no hayamos resuelto lo anterior y más grave o urgente, se obstaculizaría todo progreso moral de la humanidad. No se habría podido liberar nunca a los esclavos negros en el sur de los Estados Unidos, por ejemplo, hasta tanto no se emanciparan al tiempo a todas las mujeres.»

\section{EL FALLO}

Los magistrados que han votado a favor del recurso del PP consideran que la norma catalana menoscaba las competencias estatales en materia de cultura, en cuanto que afecta a una manifestación común como son las corridas de toros e impide en Cataluña el ejercicio de la competencia estatal dirigida a conservar esa tradición cultural que ha protegido el legislador estatal a través de una Ley posterior a la impugnada. Una vez más, este fallo «considera que la norma catalana estaría impidiendo la subsistencia de la tauromaquia en España y por ello oponiéndose a lo pretendido por la ley estatal, afirmación evidentemente fuera de la realidad, pero que es el único soporte a partir del cual subsume los hechos del caso en su nueva y revolucionaria doctrina general sobre el reparto de competencias». ${ }^{21}$

Hay que resaltar que el Tribunal Constitucional, siguiendo el «Suplico» del recurso presentado por el PP, acuerda declarar la inconstitucionalidad del art. 1 de la Ley 28/2010 (prohibición de corridas de toros), pero no del artículo 2 de este cuerpo legal (eliminación de la excepción a la prohibición de corridas de toros), a pesar de que a la

${ }^{21}$ Boix Palop, Andrés. «Ovación y vuelta al ruedo para el Tribunal Constitucional». Blog de la Revista Catalana de Dret Públic [en línia]. [Barcelona: Escola d'Administració Pública de Catalunya], 23 novembre 2016.

(C) UNED. Revista de Derecho UNED, núm. 22, 2018 
luz del art. 39.1 de la Ley Orgánica 2/1979, de 3 de octubre, del Tribunal Constitucional ${ }^{22}$, más allá del concreto petitum del PP en su recurso, hubiera podido pronunciarse no solo sobre la prohibición expresa de las corridas de toros sino también sobre la eliminación de la excepción a la prohibición.

Esto tiene unos efectos que no debemos soslayar:

La Ley 28/2010, de 3 de agosto, aprobó dos artículos ambos interrelacionados y vinculantes de tal manera que sólo conjuntamente adquieren plenamente sentido:

- El artículo $1^{23}$, que añadió al artículo 6.1 del DL 2/2008, un nuevo supuesto de prohibición de espectáculos en el apartado f) consistente en «Las corridas de toros y los espectáculos con toros que incluyan la muerte del animal y la aplicación de las suertes de la pica, las banderillas y el estoque, así como los espectáculos taurinos de cualquier modalidad que tengan lugar dentro o fuera de las plazas de toros, salvo las fiestas con toros a que se refiere el apartado $2 »$.

— El artículo $2^{24}$, que eliminó del artículo 6.2 del DL 2/2008, el apartado a) relativo a la exclusión de las corridas de toros como excepción histórica de las prohibiciones de espectáculos con animales. Dicho artículo 6.2 a) excluía de estas prohibiciones «La fiesta de los toros en las localidades donde, en la fecha de entrada en vigor de la Ley 3/1988, de 4 de marzo, de protección de los animales, hubiera plazas construidas para celebrar, a las que se debe prohibir el acceso a las personas menores de catorce años». Este artículo 2 de la Ley 28/2010, que no fue

22 «Cuando la sentencia declare la inconstitucionalidad, declarará igualmente la nulidad de los preceptos impugnados, así como, en su caso, la de aquellos otros de la misma Ley, disposición o acto con fuerza de Ley a los que deba extenderse por conexión o consecuencia».

${ }^{23}$ Ley 28/2010. Artículo primero. Adición de una letra al apartado 1.

Se añade una letra, la f, al apartado 1 del artículo 6 del texto refundido de la Ley de protección de los animales, aprobado por el Decreto legislativo 2/2008, con el siguiente texto: «f) Las corridas de toros y los espectáculos con toros que incluyan la muerte del animal y la aplicación de las suertes de la pica, las banderillas y el estoque, así como los espectáculos taurinos de cualquier modalidad que tengan lugar dentro o fuera de las plazas de toros, salvo las fiestas con toros a que se refiere el apartado 2.»

${ }^{24}$ Ley 28/2010. Artículo segundo. Supresión de una letra del apartado 2.

Se suprime la letra a del apartado 2 del artículo 6 del texto refundido de la Ley de protección de los animales, aprobado por el Decreto legislativo 2/2008, que queda redactado del siguiente modo: «2. Quedan excluidas de estas prohibiciones las fiestas con toros sin muerte del animal (correbous) en las fechas y localidades donde tradicionalmente se celebran. En estos casos, está prohibido inferir daño a los animales.» 
impugnado, dejó intacto el apartado b) relativo la exclusión de los correbous, que pasó a ser el apartado a), conservando esta excepción de toros sin muerte, pero manteniendo también íntegra la eliminación de la excepción histórica de corridas de toros.

La redacción del artículo 6.2 del DL 2/2008 antes de la Ley 28/2010 era la siguiente:

«Quedan excluidas de estas prohibiciones:

a) La fiesta de los toros en las localidades donde, en la fecha de entrada en vigor de la Ley 3/1988, de 4 de marzo, de protección de los animales, hubiera plazas construidas para celebrar, a las que se debe prohibir el acceso a las personas menores de catorce años.

b) Las fiestas con toros sin muerte del animal (correbous) en las fechas y localidades donde tradicionalmente se celebran. En estos casos, está prohibido inferir daños a los animales».

En pocas palabras, en la Ley 28/2010, había otro artículo 2, que el Tribunal Constitucional no declara inconstitucional. En este artículo 2, la Ley 28/2010 suprimió la letra a) del artículo 6.2 del DL 2/2008, donde desde 1988 existía la excepción de las corridas de toros.

La lista de espectáculos prohibidos del art. 6.1 es ejemplificativa, y únicamente las excepciones actúan como instrumentos que impiden legalmente llevar a cabo las actividades pertinentes; en caso contrario carecería de sentido la excepción (o mención permisiva expresa) de los correbous en el artículo 6.2.

En definitiva, después de la Sentencia, ya no existe el apartado f) del artículo 6.1 del DL 2/2008, pero tampoco hay rastro de la excepción histórica que legalizaba las corridas de toros. Los artículos 6.1 y 6.2 del Decreto Legislativo 2/2008, después de la Sentencia, han quedado redactado así ${ }^{25}$ (el subrayado es mío):

Artículo 6. Prohibición de peleas de animales y otras actividades

1. Se prohíbe el uso de animales en peleas y espectáculos u otras actividades si les pueden ocasionar sufrimiento o pueden ser objeto de burlas o tratamientos antinaturales, o bien si pueden BOE

${ }^{25}$ Decreto Legislativo 2/2008, de 15 de abril, texto consolidado publicado en el https://www.boe.es/buscar/pdf/2008/DOGC-f-2008-90016-consolidado.pdf 
herir la sensibilidad de las personas que los contemplan, tales como los siguientes:

a) Peleas de perros.

b) Peleas de gallos.

c) Matanzas públicas de animales.

d) Atracciones feriales giratorias con animales vivos atados y otras asimilables.

e) Tiro al pichón y otras prácticas asimilables.

g) Los espectáculos de circo con animales pertenecientes a la fauna salvaje.

2. Quedan excluidas de estas prohibiciones las fiestas con toros sin muerte del animal (correbous) en las fechas y localidades donde tradicionalmente se celebran. En estos casos, está prohibido inferir daño a los animales.

De esta forma, se ha mantenido la supresión de la excepción para hacer corridas de toros en Catalunya en el artículo 6.2 del DL $2 / 2008$ y únicamente ha anulado el espectáculo taurino de una lista ejemplificativa, no tasada (art. 6.1), en la que además se encuentra una actividad que sí fue prohibida en el pasado consistente en «matanzas públicas de animales» (art. 6.1c), que es lo que sucede en una corrida de toros. A la mayoría del Pleno del Tribunal le ha parecido correcto mantener la supresión de la excepción de celebrar corridas de toros, que era una de las finalidades de la Ley 28/2010, cuestión que parece ignorar la Sentencia, ya que incluso en su Fundamento Jurídico 3, llega a afirmar de forma aplastante que «...su único contenido (el de la Ley 28/2010) es el de añadir un apartado en uno de los preceptos de la Ley de protección de los animales», desconociendo los antecedentes normativos básicos de la norma cuya anulación declaran. De este modo, la legislación vigente catalana ha quedado como en Canarias, en la que no se hace ninguna mención a las corridas de toros, aceptándose pacíficamente que la Ley canaria fue el primer supuesto de abolición de esta actividad. Así lo ha entendido también el Magistrado don Juan Antonio Xiol Ríos, que en su voto particular emitido hace constar lo siguiente: «... la Ley 8/1991, de 30 de abril, de protección de los animales de las Islas Canarias, precisamente por no excepcionar los espectáculos taurinos de la prohibición de la utilización de animales en espectáculos y otras actividades que conlleven maltrato, crueldad o sufrimiento, como sí hace con las peleas de gallos, es entendida con carácter general por la doctrina como 
el primer exponente del prohibicionismo de los espectáculos taurinos en España».

\section{EL ALCANCE DE LA NORMATIVA TAURINA DE LAS COMUNIDADES AUTÓNOMAS DESPUÉS DE LA SENTENCIA DEL TRIBUNAL CONSTITUCIONAL}

A estas alturas, es necesario hacer una breve descripción del marco legal y competencial de los espectáculos taurinos en España.

La Constitución Española de 1978 no realiza ninguna mención a los espectáculos y festejos taurinos.

La regulación jurídica de las corridas de toros está contenida con carácter general en la Ley 10/1991, de 4 de abril, sobre potestades administrativas en materia de espectáculos taurinos, cuyo objeto es «la regulación de las potestades administrativas relacionadas con la preparación, organización y celebración de los espectáculos taurinos, al objeto de garantizar los derechos e intereses del público que asiste a ellos $y$ de cuantos intervienen en los mismos» (art. 1) y se aplica en defecto de la normativa autonómica (disposición adicional) ${ }^{26}$.

El Real Decreto 145/1996, de 2 de febrero, por el que se modifica y da nueva redacción al Reglamento de Espectáculos Taurinos, desarrolla la Ley anterior 10/1991, de 4 de abril, y por tanto tiene el mismo objeto y ámbito de aplicación (véase su art. 1) que la misma. La Disposición Adicional primera de este Real Decreto reitera el carácter subsidiario y supletorio del Reglamento estatal: "Lo previsto en el presente Reglamento será de aplicación general en todo el territorio español, en los términos de la disposición adicional de la Ley 10/1991, de 4 de abril», es decir, "...en defecto de las disposiciones especificas que puedan dictar las Comunidades Autónomas...». La explicación de la supletoriedad del Reglamento la encontramos en el mismo preámbulo de este Real Decreto: "En lo que se refiere a las competencias normativas y ejecutivas de las Comunidades Autónomas, el Reglamento ha sido absolutamente escrupuloso con lo dispuesto en las atribuciones estatutarias, respetando y preservando el ámbito de autonomía correspondientes, de acuerdo con la Ley 10/1991. Es preciso resaltar, al respecto, que desde la aprobación del Reglamento en el año 1992 se han pro-

26 «Lo establecido en la presente Ley será de aplicación general en defecto de las disposiciones especificas que puedan dictar las Comunidades Autónomas con competencia normativa en la materia, correspondiendo su ejecución a los órganos competentes de aquellas, sin perjuicio de las facultades atribuidas al Estado en relación con los espectáculos taurinos.» 
ducido sustanciales modificaciones en relación con las Administraciones públicas competentes_sobre los espectáculos taurinos». En efecto, la Ley Orgánica 9/1992, de 23 de diciembre, de transferencia de competencias a Comunidades Autónomas que accedieron a la autonomía por la vía del artículo 143, y la posterior reforma en marzo de 1994, como consecuencia de aquélla, de los Estatutos de Autonomía de 10 Comunidades Autónomas han llevado a la práctica generalización de la competencia autonómica sobre los espectáculos públicos».

Es decir, ya en el año 1996, el mismo Reglamento taurino nacional reconocía que ya se habían producido las modificaciones en el orden estatutario que permitirían a las Comunidades Autónomas que habían asumido en sus Estatutos la competencia en materia de espectáculos, regular sus propios reglamentos taurinos (como así ha sucedido en gran parte de las Comunidades Autónomas).

La Ley 18/2013, de 12 de noviembre, para la regulación de la Tauromaquia como patrimonio cultural, se aprobó como consecuencia directa de la prohibición de las corridas de toros en Catalunya con la intención de derogar dicha prohibición. Sin embargo, esta Ley no pudo desplegar ningún efecto vinculante para alterar el régimen competencial descrito en el bloque de constitucionalidad y en el contexto legal mencionado.

Desde el punto de vista autonómico, es preciso recordar con carácter previo que el legislador estatal no pudo imponer una regulación homogénea del desarrollo de las corridas de toros en el territorio nacional. Por ello se han dictado diversas normas reguladoras de los espectáculos taurinos autonómicos sobre la celebración del espectáculo taurino. Así, en el ejercicio de las competencias que las Comunidades Autónomas tienen sobre espectáculos públicos, la mayoría de éstas ha previsto la regulación de los espectáculos taurinos y, en algunos casos, incluso, han aprobado su reglamento taurino específico: este es el caso de Navarra (Decreto Foral 249/1992, de 29 de junio, por el que se aprueba el Reglamento de espectáculos taurinos); Madrid (Decreto 112/1996, de 25 de julio, por el que se aprueba el Reglamento de Espectáculos Taurinos Populares); Aragón (Decreto 223/2004, de 19 de octubre, del Gobierno de Aragón, por el que se aprueba el Reglamento de Espectáculos Taurinos); Andalucía (Decreto 68/2006, de 21 de marzo, por el que se aprueba el Reglamento Taurino de Andalucía); Castilla y León (Decreto 57/2008, de 21 de agosto, por el que se aprueba el Reglamento General Taurino de la Comunidad de Castilla y León); País Vasco (Decreto 124/2010, de 27 de abril, de modificación del Decreto por el que se aprueba el Reglamento de Espectáculos Taurinos; La Rioja (Decreto 27/2011, de 8 de abril, por el que se regu- 
lan los espectáculos taurinos populares en la Comunidad Autónoma de La Rioja); Castilla-La Mancha (Decreto 38/2013, de 11/07/2013, por el que se aprueba el Reglamento de los festejos taurinos populares de Castilla-La Mancha); Extremadura (Decreto 35/2017, de 28 de marzo, por el que se modifica el Decreto 187/2010, de 24 de septiembre, por el que se aprueba el Reglamento de Festejos Taurinos Populares de Extremadura).

Hay que destacar que los Reglamentos de Madrid, Castilla la Mancha y Extremadura prohibieron algunas modalidades de festejos taurinos especialmente crueles con los animales, como el toro embolado y enmaromado. Igualmente, resaltar que prácticamente todas las normas autonómicas anteriores hacen incidencia directa en aspectos regulados en el Reglamento taurino aprobado por el Real Decreto 145/1996, de 2 de febrero, alterando con mayor o menor alcance dicha norma estatal. Todo ello encuentra justificación en el hecho de que esta normativa estatal es de carácter supletorio y en virtud del principio de subsidiariedad que rige en esta materia taurina, en tales Comunidades Autónomas, lo previsto en dicho Reglamento estatal es de aplicación solo en lo que no contradiga lo previsto en dichas normas autonómicas. En este sentido, se puede constatar que diversas Comunidades Autonómicas han hecho uso de esta competencia de regulación de los espectáculos taurinos dictando normas que llegan incluso a modificar sustancialmente el Reglamento taurino estatal por motivos de bienestar animal, sin que hasta la fecha se haya presentado recurso alguno ante el Tribunal Constitucional.

El ejemplo más paradigmático se encuentra en el Decreto 68/2006, de 21 de marzo, por el que se aprueba el Reglamento Taurino de Andalucía, que supuso cambios importantes en la lidia de las reses para minimizar el sufrimiento del toro. Por ejemplo, en la suerte de varas se reducen las dimensiones de la puya y el número e intensidad de los puyazos se dejan a decisión del matador; en la suerte suprema se modifican los tiempos para primar la rápida muerte del animal, de forma que la faena dure aproximadamente 10 minutos, contando también los tres avisos a partir de la entrada a matar; se disminuye el peso del peto del caballo del picador; se exige la presencia de un puntillero profesional; y se hace mención especial a los análisis antidoping que podrán hacerse a los toros si su comportamiento es anormal. También la normativa de Aragón, a través del Decreto 223/2004, de 19 de octubre, del Gobierno de Aragón, por el que se aprueba el Reglamento de Espectáculos Taurinos en Aragón, ya introdujo aspectos relativos a la protección de los animales que modificaron el Reglamento estatal: por ejemplo, en las plazas de toros permanentes existe 
la obligación de que en corrales dispongan de comedores y bebederos suficientes para garantizar el bienestar de los animales ubicados en su interior; y los veterinarios tienen la obligación de cumplir con las normas de bienestar animal, en especial, durante el transporte y la disposición del plan de viaje.

Otro ejemplo de cómo la normativa autonómica procedió a modificar la estatal sin reacción alguna por parte del Estado, propiciando una mayor protección para el animal (en este caso evitando su muerte) se encuentra en el Decreto 183/2008, del País Vasco, por el que se aprueba el Reglamento de espectáculos taurinos, que admite el indulto de toros y novillos en todas las plazas permanentes, incluidas las de tercera categoría, mientras que el Reglamento estatal únicamente permite que los toros (no novillos) que se encuentren en plazas de primera y segunda categoría sean merecedores de dicho indulto.

Una explicación que clarifica esta situación legal se ofrece en el voto particular emitido por el magistrado Juan Antonio Xiol en la Sentencia objeto de análisis, que literalmente declara: "El nivel de densidad normativa en algunas Comunidades Autónomas ha llegado al limite de aprobar reglamentos taurinos propios con una regulación acabada del completo desarrollo técnico de las corridas de toros que hace innecesario en sus territorios la aplicación de la normativa subsidiaria que en la materia representa el Real Decreto 145/1996, de 2 de febrero, por el que se aprueba el Reglamento de espectáculos taurinos estatal. Esas Comunidades Autónomas han sido Andalucía (Decreto 68/2006, de 21 de marzo, modificado por Decreto 278/2011, de 20 de septiembre); Aragón (Decreto 223/2004, de 19 de octubre, modificado por Decreto 193/2005, de 29 de septiembre); Castilla y León (Decreto 57/2008, de 21 de agosto); Navarra (Decreto Foral 249/1992, de 29 de junio); y País Vasco (Decreto 281/1996, de 3 de diciembre; posteriormente sustituido por el Decreto 183/2008, de 11 de noviembre, modificado por Decreto 124/2010, de 27 de abril). En ese sentido, el contraste de la evolución legislativa estatal y autonómica en materia de espectáculos taurinos acredita el pacífico reconocimiento de que (i) los espectáculos taurinos forman parte de la competencia autonómica exclusiva en materia de espectáculos públicos que han asumido de manera global todas las Comunidades Autónomas incluyendo la Comunidad Autónoma de Cataluña; y (ii), como tal competencia exclusiva y en toda la extensión que esto supone, las Comunidades Autónomas mantienen la posibilidad de establecer normativas completas de regulación taurina que incluyen todos los aspectos técnicos del desarrollo de las corridas de toros prevalentes a la establecida de manera supletoria - sólo en defecto de desarrollo autonómico- por la normativa estatal. En resolución, se 
reconoce como exclusiva de las Comunidades Autónomas la competencia para decidir no sólo sobre aspectos de policía de espectáculos, sino sobre aspectos relativos a, por ejemplo, el desarrollo de los tercios de la lidia, las ejecuciones de las suertes de varas, de banderillas o la suerte suprema».

El último ejemplo del reconocimiento constitucional de la competencia autonómica para dictar normas regulatorias de los espectáculos taurinos, lo constituye el Decreto-ley 2/2016, de 19 de mayo, por el que se prohíbe la muerte de las reses de lidia en presencia del público en los espectáculos taurinos populares y tradicionales en Castilla y León. Dicho Decreto-Ley, que prohibió la muerte pública de las reses, tuvo una afectación directa en la celebración del festejo taurino conocido como «El Toro de la Vega», cuya regulación se concretaba en una norma de carácter municipal. Este conflicto competencial motivó un recurso del Ayuntamiento de Tordesillas ante el Tribunal Constitucional, por entender que invadía su autonomía municipal. Dicho recurso fue inadmitido mediante Auto del Tribunal Constitucional núm. 206/2016, de 13 de diciembre de 2016, que proclamó que la prohibición de la muerte del animal tenía su encaje competencial en una norma autonómica: «Conforme a las referidas competencias, la Comunidad Autónoma puede, en principio, afrontar la regulación, desarrollo y organización de tales eventos lo que puede incluir, desde el punto de vista competencial, la prohibición de dar muerte de las reses de lidia en presencia del público en los espectáculos taurinos populares y tradicionales. Además, resulta relevante que la intervención normativa se ha ceñido a la protección del animal al consistir en la prohibición de matar al toro en presencia del público y no a otro aspecto de la regulación del espectáculo.»

De este modo, a través de este Auto, que es posterior a la Sentencia de Catalunya, el Tribunal Constitucional entiende que la prohibición de la muerte del toro por parte de las CCAA queda inserida dentro de los conceptos de «regulación, desarrollo y organización» de espectáculos taurinos.

\section{CONCLUSIÓN}

Llegados a este punto, es preciso concluir que según la legislación estatal y autonómica de carácter taurina expuesta en el epígrafe anterior, los espectáculos taurinos están sometidos al régimen previsto para los espectáculos públicos, incluidos las corridas de toros, sobre los que las Comunidades Autónomas tienen competencia exclusiva, y al régimen referente a la protección de los animales, aspecto sobre el que las Comunidades Autónomas también tienen plenas competencias. 
Se ha comprobado asimismo que la regulación del desarrollo de las corridas de toros no es uniforme para todo el territorio español, aplicándose la normativa estatal de forma supletoria (Real Decreto $145 / 1996$, de 2 de febrero), por lo que no cabe impedimento alguno al ejercicio de las competencias de protección de los animales de las CCAA en la regulación de esta actividad.

Para adecuarse a la doctrina constitucional sin extralimitarse en sus competencias, la normativa autonómica no puede comprender una prohibición en bloque de la actividad de las corridas de toros, si no una regulación para garantizar la protección y el cuidado de los animales, que por ejemplo impida la realización de heridas infligidas al toro y su muerte. En efecto, el carácter exclusivo de la competencia autonómica en materia de espectáculos junto con la existente en materia de protección animal, puede comprender la regulación, desarrollo y organización de tales eventos, lo que podría incluir, desde el punto de vista competencial, la facultad de impedir la tortura y muerte del toro por razones vinculadas a la protección animal. Por tanto, queda margen en la legislación autonómica para regular el espectáculo y proteger los animales. Así se deduce de los establecido por la Sentencia 177/2016, del Tribunal Constitucional, respecto del recurso del Partido Popular interpuesto en contra de la Ley catalana ${ }^{27}$, y de allí que se haya aprobado por el Parlamento Balear la Ley 9/2017, de 3 de agosto, de regulación de las corridas de toros y de protección de los animales en las Iles Balears ${ }^{28}$, que establece requisitos de bienestar y protección de los animales en el embarque, transporte, desembarque, en los corrales y chiqueros y durante la celebración de las corridas de toros. Esta Ley Balear no prohíbe en absoluto las corridas de toros, que es lo que el TC declaró inconstitucional, sino que procede a regularlas para la protección de los animales.

${ }^{27}$ FJ 7: "Ello no significa que la Comunidad Autónoma, no pueda, en ejercicio de sus competencias sobre ordenación de espectáculos públicos, regular el desarrollo de las representaciones taurinas; ni tampoco que, en ejercicio de su competencia en materia de protección de animales, pueda establecer requisitos para el especial cuidado y atención del toro bravo.»

${ }^{28}$ https://www.boe.es/boe/dias/2017/09/15/pdfs/BOE-A-2017-10542.pdf 